\title{
EQUILIBRIUM, THERMODYNAMIC AND KINETIC STUDIES TO STUDY THE SORPTION OF RHODAMINE-B BY MOROCCAN CLAY
}

\author{
ELASS K.1,* \\ LAACHACH A. ${ }^{1}$ \\ AZZI M. ${ }^{2}$
}

\author{
${ }^{1}$ Environmental Metrology Laboratory \\ National School of Mineral Industry (ENIM) \\ BP: 753 Agdal-Rabat, Morocco \\ ${ }^{2}$ Laboratory of Electrochemistry and Environment \\ Faculty of Science Aïn Chock \\ Casablanca, Morocco
}

*to whom all correspondence should be addressed:

Accepted: $17 / 04 / 13$ e-mail: khelass@gmail.com

\begin{abstract}
This study aimed to evaluate the sorption capability of an inexpensive and easily available Moroccan clay, called locally Ghassoul, to remove Rhodamine B (Rh-B) from aqueous solution. Experimental results showed that the equilibrium sorption data fitted well with the Langmuir isotherm and the monolayer sorption capacity was estimated as $448 \mathrm{mg} \mathrm{g}^{-1}$ at $298 \mathrm{~K}$. Kinetic analyses showed that the sorption rate was more accurately represented by a pseudo second-order model. The intra-particle diffusion was involved in the overall rate of the sorption process but it was not the only ratecontrolling step. The calculated thermodynamics parameters showed the spontaneous and the endothermic nature of the sorption process. The activation energy found to be $5.36 \mathrm{~kJ} \mathrm{~mol}^{-1}$ could indicate a physical sorption process. The obtained results confirmed the applicability of this clay as an efficient and economical adsorbent for cationic dyes from contaminated water.
\end{abstract}

KEYWORDS: sorption, natural clay, Rhodamine B, isotherm, Kinetic.

\section{INTRODUCTION}

Industries such as textile, leather, paper, plastics, etc., use dyes in order to color their products and also consume substantial volumes of water. As a result, they generate a considerable amount of colored wastewater (Ravi et al., 2005). It is estimated that more than 100,000 commercially available dyes with over $7 \times 10^{5}$ tones of dyestuff produced annually (Rafatullah et al., 2010). Their presence in water, even at very low concentrations, is highly visible and undesirable and may significantly affect photosynthetic activity in aquatic life. The synthetic origin and complex aromatic structures of dyes make them stable and difficult to be biodegraded (Forgacs et al., 2004). Many treatment processes have been applied for the removal of dyes from wastewater such as coagulation, flocculation, ozonation, membrane filtration, Fentons reagent, ion exchange and biological treatment (Gupta and Suhas, 2009). Sorption has been found to be superior to other techniques for wastewater treatment in terms of initial cost, flexibility and simplicity of design, ease of operation and insensitivity to toxic pollutants. The most commonly used adsorbent in industrial wastewater treatment systems is activated carbon because it has a large specific surface area, although it is a bit expensive to run such systems. The use of clay materials is becoming popular due to their low-cost, abundant availability, non-toxicity and potential for ion exchange. A number of clay materials: sepiolite (Dogan et al., 2006), kaolinite (Karaoğlu et al., 2010), perlite (Dogan and Alkan, 2003), montmorillonite (Wang et al., 2004), pyrophyllite (Sheng et al., 2009), and bentonite (Tahir and Rauf, 2006) have been investigated for removal of dyes. These clay minerals are of interest according to their variety of structural and surface properties, high chemical stability, high specific surface area and high sorption capacity (Gürses et al., 2004). 
In this work, we attempt to investigate the potential of an abundant Moroccan clay, called locally Ghassoul, as an adsorbent of cationic dyes from aqueous solutions. This mineral clay (also known as Rassoul or Ghasoul) comes from the only deposit in the world, located at the East side of the Middle Atlas Mountains, in the Moulouya valley, approximately $200 \mathrm{~km}$ away from Fes (Benhammou et al., 2009). For several centuries, Ghassoul clay has been used in natural cosmetic products (soap, shampoo, skin conditioner). Currently, it is marketed for its detergent and grease-removing properties. This Moroccan clay has been the subject of several recent studies in order to develop new industrial applications. Benhammou et al. (2005a, 2005b, 2007) studied the sorption of heavy metals in aqueous solution on raw and on organic- and inorganic-modified Ghassoul. El Ass et al., (2010) studied the sorption of Basic dye in aqueous solution onto raw Ghassoul.

\section{MATERIALS AND METHODS}

\subsection{Adsorbent and adsorbate}

The clay sample used in this investigation was taken from deposits in the careers of Tamdalet in the province of Boulemane, Morocco. Clay sample was washed in ordered to remove carbonates, soluble salts and organic matters. Then, the clay fine fraction was separated by siphoning techniques (El Ass et al., 2010). The washed clay was dried at $70{ }^{\circ} \mathrm{C}$ for $24 \mathrm{~h}$, ground then sieved by $140 \mu \mathrm{m}$ sieves.

Rhodamine $\mathrm{B}$ (Rh-B, C.I. No. $45170, \mathrm{C}_{28} \mathrm{H}_{31} \mathrm{~N}_{2} \mathrm{O}_{3} \mathrm{Cl}, \mathrm{MW}=359.9 \mathrm{~g} / \mathrm{mol}, 95 \%$ purity) is a highly water soluble, basic dye of the xanthene class and is widely used in biological, analytical, and optical sciences. It is reported that Rh-B is hazardous in case of skin contact (irritant), of eye contact (irritant), of ingestion, of inhalation. It is harmful to aquatic life with long lasting effects. The concentration of Rh-B dye was determined spectrophotometrically at $\lambda_{\max }=554 \mathrm{~nm}$, by using double beam UV spectrophotometer, Shimadzu 160 UV-visible.

\subsection{Sorption measurements}

Sorption experiments were carried out by shaking $100 \mathrm{mg}$ Ghassoul sample with $100 \mathrm{ml}$ aqueous solutions of Rh-B of desired concentrations. All sorption experiments were performed at temperature $298 \mathrm{~K}$ and dye solution $\mathrm{pH}(\sim 7)$, except those in which the effects of temperature and $\mathrm{pH}$ were investigated. An adsorbent dose of $1 \mathrm{~g} / \mathrm{L}$ was kept constant for all of the sorption experiments.

The preliminary experiment revealed that about 40-50 min was required for the sorption process to reach equilibrium. Therefore, a contact period of $90 \mathrm{~min}$ was finally selected for all of the equilibrium tests. The solution and solid phase were separated by centrifugation at $4000 \mathrm{rpm}$ for $15 \mathrm{~min}$. A 10-ml aliquot of the supernatant was removed and analyzed.

The sorption capacity of dyes was then calculated using the relation:

$\mathrm{q}_{\mathrm{e}}=\frac{\mathrm{C}_{0}-\mathrm{C}_{\mathrm{e}}}{\mathrm{m}} \cdot V$

where $C_{0}$ and $C_{e}\left(\mathrm{mg} \mathrm{l}^{-1}\right)$ are the liquid-phase concentrations of dye at initial and equilibrium time, respectively. $V(\mathrm{~L})$ is the volume of the solution, and $m(\mathrm{~g})$ is the mass of adsorbent used.

For kinetic studies, $0.5 \mathrm{~g}$ of Ghassoul clay was added into $0.5 \mathrm{I}$ of Rh-B solutions with different initial concentrations $\left(200-800 \mathrm{mg} \mathrm{l}^{-1}\right)$. The dye sorption amounts were determined by analyzing the solution at appropriate time intervals. The effect of temperature on the sorption kinetic was carried out by performing the sorption experiments at various temperatures $(298,308$, and $318 \mathrm{~K})$.

Blanks containing no dyes were used for each series of experiments. Each experimental point was an average of three independent sorption tests.

\section{RESULTS AND DISCUSSIONS}

\subsection{Characterization of Ghassoul clay}

Mineralogical identification of the sample clay was performed by X-ray diffraction (XRD). The XRD pattern of Ghassoul clay (Fig. 1) shows that the dominant phase is the stevensite with the presence of quartz and dolomite. The chemical composition showed that the Ghassoul clay was principally made up of $\mathrm{SiO}_{2}(58.16 \mathrm{wt} \%)$ and $\mathrm{MgO}(27.44 \mathrm{wt} \%)$. The surface area, measured by the $\mathrm{N}_{2}-\mathrm{BET}$ method, was $137 \mathrm{~m}^{2} \mathrm{~g}^{-1}$. This high value, compared with other clays, revealed the existence of a high porosity responsible for the strong capacity of this material to fix some cations (Benhammou et al., 2005a). The cation exchange capacity was $79 \mathrm{meq} / 100 \mathrm{~g}$, relatively large, compared to the value for natural stevensite (41 meq/l00 g), reported by Takahashi et al. (1997). 


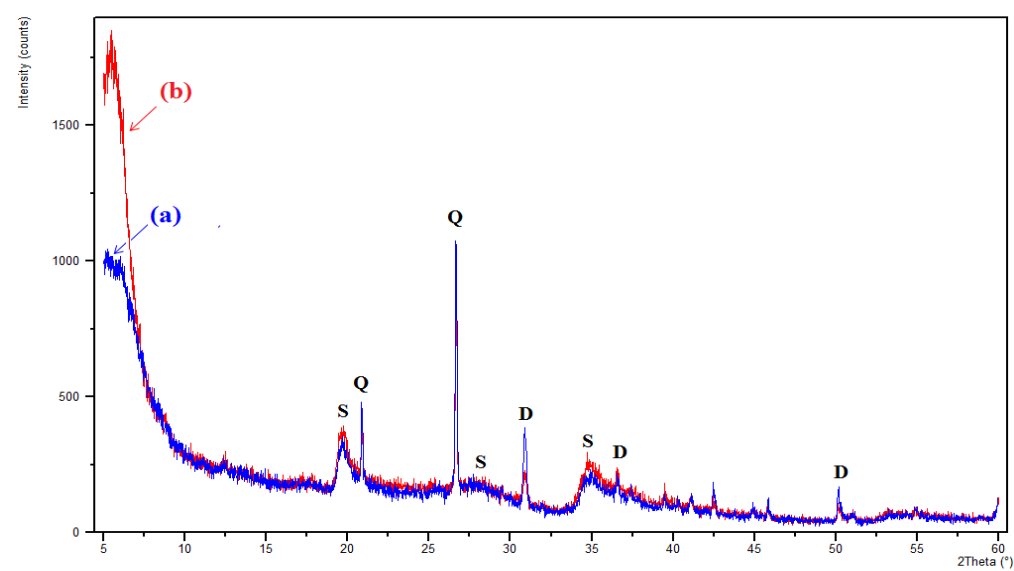

Figure 1. XRD diagrams of (a) the raw sample and (b) the separated fine fraction of Ghassoul clay

\subsection{Sorption studies}

\subsubsection{Effect of solution $\mathrm{pH}$}

The sorption of Rh-B onto Ghassoul clay was studied in a pH range of $3-10$ at $298 \mathrm{~K}$ and at initial dye concentration of $500 \mathrm{mg} \mathrm{l}^{-1}$. As seen from figure $2 \mathrm{a}$, maximum sorption occurs at basic $\mathrm{pH}$. The $\mathrm{pH}$ effect on dye sorption can be attributed to the electrostatic attraction between the negatively charged surface and the positively charged dye molecules. Indeed at $\mathrm{pH} 2-12$, Ghassoul clay particles are formed of negatively charged layers responsible via Coulombic attractions of the strong retention of cationic dyes (Bouna et al., 2010).

\subsubsection{Effect of ionic strength}

The influence of ionic strength on the sorption of Rh-B onto Ghassoul clay was studied in the range of 0.01 and $0.20 \mathrm{~mol} \mathrm{I}^{-1} \mathrm{NaCl}$ concentration at $298 \mathrm{~K}$, solution pH and at constant dye concentration of $500 \mathrm{mg} \mathrm{l}^{-1}$ (Fig. 2b). As seen in figure $2 \mathrm{~b}$, the dye sorption lightly increases with the increasing $\mathrm{NaCl}$ concentration. The presence of $\mathrm{NaCl}$ in the solution may have two opposite effects. On the one hand, since the salt screens the electrostatic interaction of opposite changes of the oxide surface and the dye molecules, the adsorbed amount should decrease with increase of $\mathrm{NaCl}$ concentration. On the other hand, the salt causes an increase in the degree of dissociation of the dye molecules by facilitating the protonation. The latter effect seems to be dominant on the sorption capacity of the surface. These results are similar to earlier findings by other workers for sorption of reactive blue 221 on kaolinite (Karaoğlu et al., 2010) and maxilon blue GRL onto sepiolite (Dogan et al., 2006).

\subsection{Sorption isotherm and equilibrium}

The equilibrium sorption of Rh-B onto Ghassoul clay was studied as a function of dye concentrations $\left(100-1000 \mathrm{mg} \mathrm{l}^{-1}\right)$. The amount of dye adsorbed $\left(q_{e}\right)$, plotted against the equilibrium concentration $\left(C_{e}\right)$ is given in figure 2c. Initially, the sorption isotherm of dye molecules shows a steeply rising part, suggesting a strong affinity of the dye molecules for the polar surface sites of clay sample. Then the amount of sorption reaches a limiting value of around $450 \mathrm{mg} \mathrm{g}^{-1}$. The equilibrium sorption of dye increases with the increase of initial dye concentration, showing the sorption process to be dependent on the initial concentration.

The analysis of the isotherm data by fitting them to different isotherm models is an important step to find the suitable model that can be used for design purposes. Two isotherm models, relating to sorption equilibrium, have been tested in the present research, namely Langmuir and Freundlich isotherm models.

Langmuir model assumes monolayer sorption onto a surface containing a finite number of sorption sites of uniform energies of sorption with no transmigration of adsorbate in the plane of surface. The Langmuir isotherm can be represented as:

$q_{e}=\frac{q_{m} K_{L} C_{e}}{1+K_{L} C_{e}}$

where $C_{e}$ is the equilibrium concentration $(\mathrm{mg} / \mathrm{L}) ; q_{e}$ the amount adsorbed per unit weight of Ghassoul clay $\left(\mathrm{mg} \mathrm{g}^{-1}\right) ; q_{\max }$ the monolayer capacity of the adsorbent $\left(\mathrm{mg} \mathrm{g}^{-1}\right), K_{L}\left(\mathrm{I} \mathrm{mg}^{-1}\right)$ a constant 
related to the affinity of the binding sites and energy of sorption. Values of $q_{\max }$ and $K_{L}$ can be calculated from the slope and intercept of the linear plot of $1 / q_{e}$ against $1 / C_{e}$.
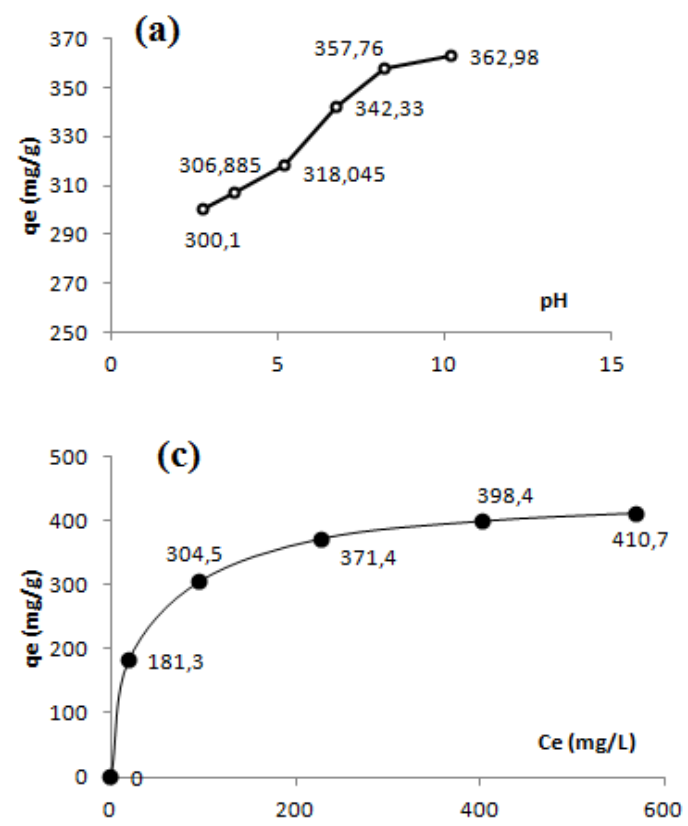
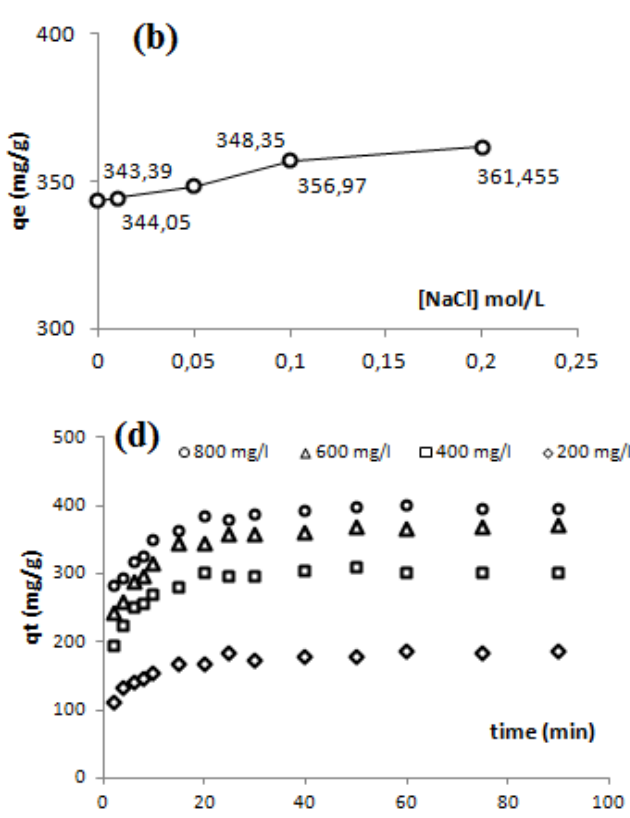

Figure 2. Plots of (a) effect of $\mathrm{pH}$, (b) effect of ionic strength, (c) sorption isotherm, (d) effect of contact time and initial dye concentrations

The Freundlich isotherm is commonly presented as :

$q_{e}=K_{F} C_{e}^{1 / n}$

where, $K_{F}$ and $n$ are the Freundlich constants related to the sorption capacity and the sorption intensity of the adsorbent, respectively. These parameters can be calculated from the intercept and the slope of the linear plot $\log \left(q_{e}\right)$ versus $\log \left(C_{e}\right)$.

Table 1. Langmuir and Freundlich parameters for the sorption of Rhodamine B onto Ghassoul clay

\begin{tabular}{cccccc}
\hline \multicolumn{3}{c}{ Langmuir constants } & \multicolumn{4}{c}{ Freundlich constants } \\
\hline $\begin{array}{c}\boldsymbol{q}_{\max } \\
\left(\mathrm{mg} \mathrm{g}^{-1}\right)\end{array}$ & $\begin{array}{c}\boldsymbol{K}_{\mathrm{L}} \\
\left(\mathrm{mg}^{-1}\right)\end{array}$ & $\boldsymbol{R}^{2}$ & $\boldsymbol{n}$ & $\boldsymbol{K}_{\boldsymbol{F}}$ & $\boldsymbol{R}^{2}$ \\
\hline 448 & 0.025 & 0.999 & 4.1 & 92.04 & 0.962 \\
\hline
\end{tabular}

The calculated values of the constants and the regression correlation coefficients $\left(R^{2}\right)$ are given in Table 1. The Langmuir isotherm was found to be linear over the whole concentration range and the correlation coefficient was extremely high (> 0.999), suggesting that the sorption of Rh-B onto Ghassoul clay closely follow a Langmuir isotherm. The Langmuir monolayer sorption capacity $q_{\max }$ was $448 \mathrm{mg} / \mathrm{g}$. Similar results have also been reported by Panneer Selvam et al. (2008) for sorption of Rhodamine B onto sodium montmorillonite and by Jiang et al. (2008) for sorption of Basic Violet 14 on bentonite.

\subsection{Sorption rate}

3.4.1. Effect of contact time and initial dye concentration

Equilibrium time is one of the most important parameters in the design of economical wastewater treatment systems. Figure $2 \mathrm{~d}$ shows the effect of contact time and initial dye concentration on sorption of Rh-B onto Ghassoul clay. It was observed that the amount of dye uptake is increased with increasing the contact time at all initial dye concentrations. Furthermore, the amount of dye adsorbed is increased with the increase in initial dye concentration. For the first $20 \mathrm{~min}$, the sorption uptake was rapid then it proceeds at a slower sorption rate and finally it attains saturation at 40 min. 
The rapid sorption at the initial contact time is due to the availability of the negatively charged surface of adsorbent which led to fast electrostatic sorption of the cationic dye molecules from the solution. Afterwards with the gradual occupancy of these sites, the sorption became less efficient, dye needed to diffuse to the sorbent surface. A similar effect was previously reported by Karaoğlu et al. (2010) for reactive blue 221 sorption on kaolinite and Wang et al. (2010) for basic dyes on activated carbon.

\subsubsection{Kinetic studies}

The kinetic study of the sorption processes provides useful data regarding the efficiency of sorption and feasibility of scale-up operations. In order to understand the behavior of the adsorbent and to examine the controlling mechanism of the sorption process, the pseudo first-order, the pseudo second order and intraparticle diffusion models were applied to test the experimental data.

The pseudo first-order rate expression of Lagergren $(\mathrm{Ho}, 2004)$ is given as:

$\log \left(q_{e}-q_{t}\right)=\log q_{e}-\frac{k_{1}}{2.303} t$

where $q_{e}$ and $q_{t}$ are the amounts of dye adsorbed on the adsorbent at equilibrium and at time $t$, respectively $(\mathrm{mg} / \mathrm{g})$ and $k_{1}$ is the rate constant of first-order sorption $\left(\mathrm{min}^{-1}\right)$. The slopes and intercepts of plots of $\log \left(q_{e}-q_{t}\right)$ vs. $t$ were used to determine the first-order rate constant $k_{1}$.

The pseudo second-order kinetic model (Kuncek and Sener, 2010) is expressed as:

$\frac{t}{q_{t}}=\frac{1}{k_{2} q_{e}^{2}}+\frac{t}{q_{e}}$

where $k_{2}$ (g/mg.min) is the rate constant of second order sorption. The slopes and intercepts of plots of $t / q_{t}$ vs. $t$ were used to calculate the second-order rate constant $k_{2}$ and $q_{e}$.

Sorption rate constants by using regression procedure are shown in Table 2 . The linear plots of $t / q t$ versus $t$ and $\log \left(q_{e}-q_{t}\right)$ vs. $t$ (Fig. $3 \mathrm{a}$ and b) show that the experimental data agree with the pseudo-second-order kinetic model. In addition, the values of calculated $q_{\mathrm{cal}}$ in the case of the second-order model are very close to the experimental values. The correlation coefficients for the second-order kinetic model are close to unity in all cases. Similar kinetic results have also been reported for the removal of Rhodamine B using iron-pillared bentonite (Mei-Fang Hou et al., 2011) and other basic dyes onto clay adsorbents (Sheng et al., 2009, Kuncek and Sener, 2010).

Table 2. Sorption kinetic rate constants and correlation coefficients for the sorption of Rhodamine B onto Ghassoul clay

\begin{tabular}{|c|c|c|c|c|c|c|c|c|c|}
\hline \multirow[b]{2}{*}{$\begin{array}{l}\text { [dye] } \\
\left(\mathrm{mg} \mathrm{l}^{-1}\right)\end{array}$} & \multirow[b]{2}{*}{$\begin{array}{l}\text { qe(exp) } \\
\left(\mathrm{mg} \mathrm{g}^{-1}\right)\end{array}$} & \multicolumn{2}{|c|}{$\begin{array}{c}\text { Pseudo-first order } \\
\text { model }\end{array}$} & \multicolumn{3}{|c|}{$\begin{array}{l}\text { Pseudo-second order } \\
\text { model }\end{array}$} & \multicolumn{3}{|c|}{$\begin{array}{c}\text { Intra-particle diffusion } \\
\text { model }\end{array}$} \\
\hline & & $\mathbf{k}_{\mathbf{1}} \times 10^{2}$ & $\mathbf{R}^{2}$ & $\begin{array}{l}\text { qe (cal) } \\
\left(\mathrm{mg} \mathrm{g}^{-1}\right)\end{array}$ & $\begin{array}{c}\mathbf{k}_{2} \times 10^{4} \\
\left(\mathrm{~g} \mathrm{~mol}^{-1} \mathrm{~min}^{-1}\right)\end{array}$ & $\mathbf{R}^{2}$ & $\underset{\mathrm{mg} \mathrm{g}^{-1} \mathrm{~min}^{-1 / 2}}{\mathbf{k}_{\mathbf{2}}}$ & $\underset{\mathrm{mg} \mathrm{g}^{-1}}{\mathbf{C}}$ & $\mathbf{R}^{\mathbf{2}}$ \\
\hline 200 & 185.80 & 2.11 & 0.938 & 190.11 & 22.7 & 0.999 & 18.96 & 90.9 & 0.911 \\
\hline 400 & 302.05 & 1.93 & 0.783 & 307.69 & 27.0 & 0.999 & 36.03 & 150.9 & 0.936 \\
\hline 600 & 370.66 & 2.71 & 0.872 & 377.36 & 13.9 & 0.999 & 44.75 & 166.2 & 0.977 \\
\hline 800 & 391.12 & 3.15 & 0.904 & 398.41 & 18.5 & 0.999 & 41.97 & 206.8 & 0.976 \\
\hline
\end{tabular}

The pseudo-first-order and pseudo-second-order kinetic models could not identify the diffusion mechanism. An intraparticle diffusion model was used to predict the rate controlling step of the sorption process. The equation, based on the theory proposed by Weber and Morris (1963), is expressed as follows:

$q_{t}=k_{p} t^{1 / 2}+C$

where $k_{p}$ is the intraparticle diffusion rate constant $\left(\mathrm{mg} / \mathrm{g} \cdot \mathrm{min}^{1 / 2}\right)$, which can be evaluated from the slope of the linear plot of $q_{t}$ versus $t^{1 / 2}$ and $C$ is the intercept, which represents the thickness of the boundary layer. In most cases, this plot gives general features of three stages: initial curved portion, followed by an intermediate linear portion and a plateau. The initial sharper, is due to the instantaneous sorption or external surface sorption (external mass transfer). The intermediate linear 
part is due to intra-particle diffusion and the plateau to the equilibrium stage where intraparticle diffusion starts to slow down due to extremely low solute concentrations in the solution.

Plot of the quantity of Rh-B adsorbed against square root of time for $C_{0}=200,400,600$ and $800 \mathrm{mg} / \mathrm{l}$ at $25{ }^{\circ} \mathrm{C}$ is shown in figure $3 \mathrm{c}$. It can be observed that the plots are not linear over the whole time range and the graphs of this figure reflect a dual nature, with initial linear portion followed by a plateau. The fact that the first curved portion of the plots seems to be absent implies that the external surface sorption (stage 1) is relatively very fast and the stage of intra-particle diffusion (stage 2) is rapidly attained. Finally, equilibrium sorption (stage 3) starts after. The dye molecules are slowly transported via intra-particle diffusion into the particles and are finally retained in the pores.

The values of $k_{p}$ and $C$ were determined from the slopes of the first linear portion, and the constants of intraparticle diffusion model are given in Table 2. It was observed that the $R^{2}$ values are close to unity, which indicates the appropriateness of the application of this model.

None of the lines passed through the origin, $C \neq 0$. This indicates that the intraparticle diffusion is not the only rate-controlling step. That is, some other mechanisms such as complexation or ionexchange may also control the rate of sorption (Ozcan et al., 2005). Previous studies have showed similar results (Baccar et al., 2010; Mane et al., 2011).

\subsection{Thermodynamic studies}

\subsubsection{Effect of temperature}

Temperature is an important parameter for the sorption process. Figure $3 d$ shows the sorption kinetics of Rh-B at 298, 308 and $318 \mathrm{~K}$ by plotting the Rh-B uptake capacity versus time at the initial dye concentration of $500 \mathrm{mg} / \mathrm{L}$. As seen in figure $3 \mathrm{~d}$, the increase in temperature leads to an increase in dye uptake, indicating that the sorption is an endothermic process. Increasing the temperature is known to increase the rate of diffusion of the adsorbate molecules across the external boundary layer and in the internal pores of the adsorbent particle, owing to the decrease in the viscosity of the solution for highly concentrated suspensions. Similar results were reported in the literature for sorption of Rhodamine B by activated carbon from bagasse pith (Gad and El-Sayed, 2009) and onto sodium montmorillonite (Panneer Selvam et al., 2008).
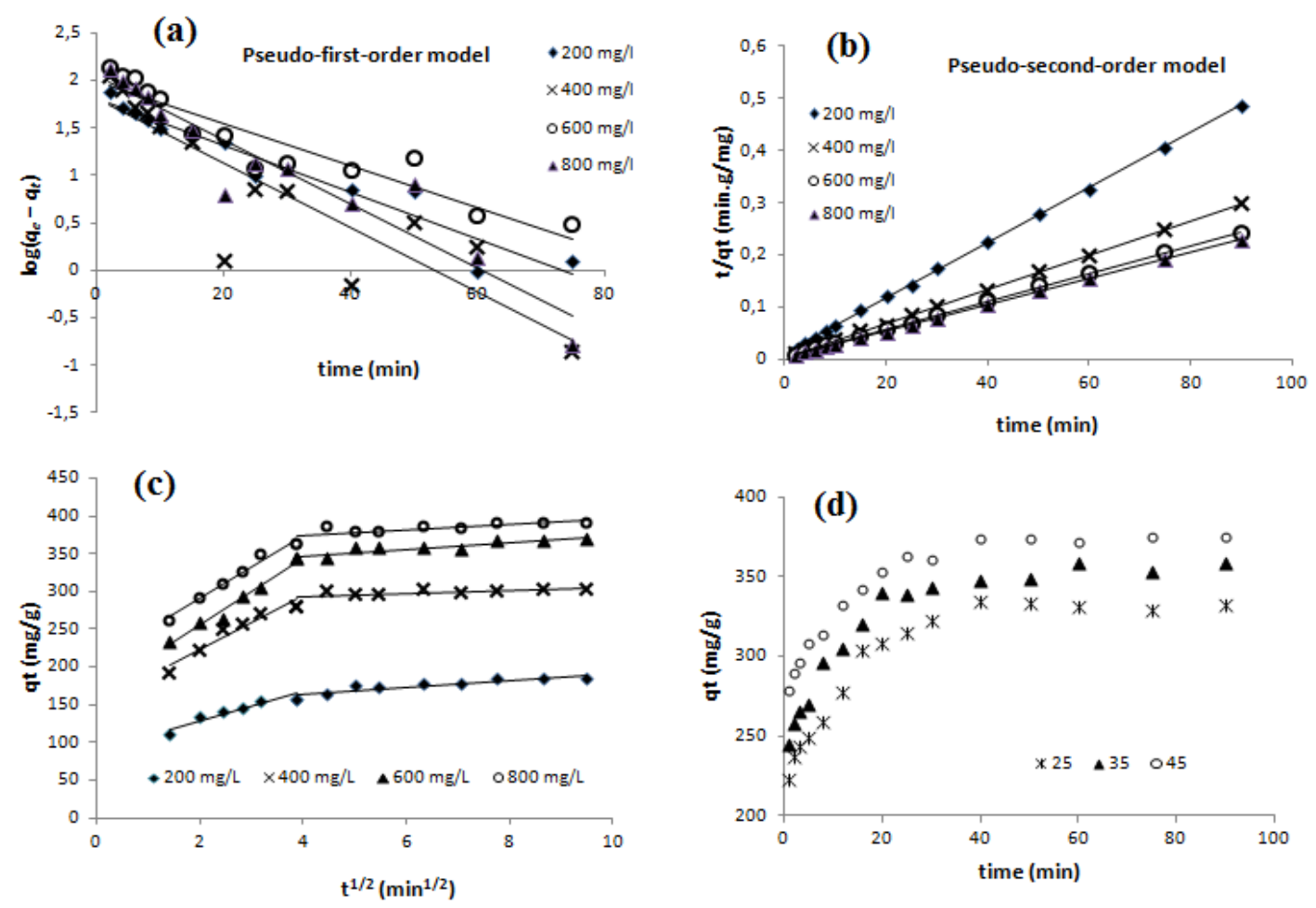

Figure 3. Plot of (a) pseudo-first-order equation, (b) pseudo-second-order equation, (c) intra-particle diffusion, (d) effect of temperature 


\subsubsection{Thermodynamic parameters}

The thermodynamic parameters provide in-depth information regarding the inherent energetic changes associated with sorption; therefore, they should be properly evaluated. The second-order rate constants listed in Table 2 are used to estimate the activation energy of Rh-B sorption onto Ghassoul clay using Arrhenius equation:

$\ln k_{2}=\ln A-\frac{E_{a}}{R T}$

where $E_{\mathrm{a}}$ is the Arrhenius activation energy $\left(\mathrm{kJ} \mathrm{mol}^{-1}\right), A$ the Arrhenius factor, $R$ the gas constant (8.314 $\mathrm{J} \mathrm{mol}^{-1} \mathrm{~K}^{-1}$ ) and $T$ is the solution temperature in Kelvin. The activation energy $E_{a}$ was determined from the slope of the Arrhenius plot of $\ln \left(k_{2}\right)$ versus $1 / T$. The magnitude of activation energy gives an idea about the type of sorption which is mainly physical or chemical. Nollet et al. (2003) suggested that the physisorption process normally had activation energy of $5-40 \mathrm{~kJ} \mathrm{~mol}^{-1}$, while chemisorption had higher activation energy $\left(40-800 \mathrm{~kJ} \mathrm{~mol}^{-1}\right)$. The value of activation energy found was very low $\left(5.36 \mathrm{~kJ} \mathrm{~mol}^{-1}\right)$ and hence it can be concluded that process is governed by interactions of physical nature. Similar result was reported for sorption of cationic methyl violet and methylene blue dyes onto sepiolite (Dogan et al., 2007).

The thermodynamic parameters such as change in standard free energy $\left(\Delta G^{\circ}\right)$, enthalpy $\left(\Delta H^{\circ}\right)$ and entropy $\left(\Delta S^{\circ}\right)$ were determined by using the following equations:

$\ln k_{c}=\frac{\Delta S^{\circ}}{R}-\frac{\Delta H^{\circ}}{R T}$

$\Delta G^{\circ}=\Delta H^{\circ}-T \Delta S^{\circ}$

where $R\left(8.314 \mathrm{~J} \mathrm{~mol}^{-1} \mathrm{~K}^{-1}\right)$ is the gas constant, $T(\mathrm{~K})$ the absolute temperature and $k_{\mathrm{c}}\left(\mathrm{I} \mathrm{g}^{-1}\right)$ is the standard thermodynamic equilibrium constant defined by $q_{\mathrm{e}} / C_{\mathrm{e}}$. By plotting a graph of $\ln \left(k_{\mathrm{c}}\right)$ versus $1 / T$, the values $\Delta H^{\circ}$ and $\Delta S^{\circ}$ can be estimated from the slopes and intercepts.

The free energy of the process at all temperatures for Rh-B sorption onto Ghassoul clay was negative indicating the feasibility of the process and the spontaneous nature of the sorption. The negative $\Delta G^{\circ}$ values increased with increased temperature $\left(-35.04,-35.65\right.$ and $-36.27 \mathrm{KJ} \mathrm{mol}^{-1}$ at 298,308 and $318 \mathrm{~K}$, respectively), indicating that the spontaneity sorption is proportional to the temperature. The positive value of $\Delta H^{\circ}\left(-16.66 \mathrm{~kJ} \mathrm{~mol}^{-1}\right)$ further confirms the endothermic nature of the sorption process. Moreover, the positive value of $\Delta S^{\circ}\left(61.68 \mathrm{~J} \mathrm{~mol}^{-1} \mathrm{~K}^{-1}\right)$ shows the increased randomness at the solid- solution interface with some structural changes in the adsorbate and adsorbent and an affinity of the Ghassoul clay particles toward Rh-B. These results are in agreement with the finding reported by Tahir et al. (2006), Ahmad et al. (2009) and Wang et al. (2010).

\section{CONCLUSIONS}

Based on the results obtained from this study, it appears that the Ghassoul clay constitutes a good adsorbent for removing cationic dyes from aqueous solution. The equilibrium up-take capacity increases with the increase of $\mathrm{pH}$ in the range of 3-10. The results show that the sorption system could be explained by the electrostatic attraction between the negatively charged surface and the positively charged dyes molecules. The sorption rate increases with the increasing initial dye concentration and the sorption kinetic is very well described by the pseudo-second-order kinetic model. The application of the intra-particle diffusion model reveals that the sorption mechanism of this dye is rather a complex process and the intra-particle diffusion is involved in the overall rate of the sorption process but it is not the only rate-controlling step. The calculated thermodynamic parameters show the spontaneous and endothermic natures of the sorption process which is favored at higher temperatures. The low value of the activation energy shows that dye sorption process by the Ghassoul clay may involve a physical sorption. The maximum sorption capacity is determined with the Langmuir isotherm and found to be $448 \mathrm{mg} / \mathrm{g}$ at $298 \mathrm{~K}$. Sorption of cationic dyes on Ghassoul clay can be considered as a simple, fast and economic method for their removal from water and wastewater. 


\section{REFERENCES}

1. Ahmad A., Rafatullah M., Sulaiman O., Ibrahim M.H., Hashim R., (2009), Scavenging behavior of meranti sawdust in the removal of methylene blue from aqueous solution, J. Hazard. Mater., 170, 357-365.

2. Baccar R., Blánquez P., Bouzid J., Fekic M., Sarrà M., (2010), Equilibrium, thermodynamic and kinetic studies on sorption of commercial dye by activated carbon derived from olive-waste cakes, Chem. Eng. J., 165, 457-464.

3. Benhammou A., Tanouti B., Nibou L., Yaacoubi A., Bonnet JP., (2009), Mineralogical and physicochemical investigation of Mg-smectite from Jbel Ghassoul, Morocco, Clays and Clay Minerals, 57, 264-270.

4. Benhammou A., Yaacoubi A., Nibou L., Tanouti B., (2005), Sorption of metal ions onto Moroccan stevensite: kinetic and isotherm studies, J. Coll. Interf. Sci., 282, 320-326.

5. Benhammou A., Yaacoubi A., Nibou L., Tanouti B., (2005), Study of the removal of mercury(II) and chromium(VI) from aqueous solutions by Moroccan stevensite, J. Hazard. Mater., B117, 243-249.

6. Benhammou A., Yaacoubi A., Nibou L., Tanouti B., (2007) Chromium(VI) sorption from aqueous solution onto Moroccan Al-pillared and cationic surfactant stevensite, J. Hazard. Mater., 140, 104109.

7. Bouna L., Rhouta B., Amjoud M., Jada A., Maury F., Daoudi L., Senocq F, (2010), Correlation between eletrokinetic mobility and ionic dyes sorption of Moroccan stevensite, Appl. Clay Sci., 48, 527-530.

8. Dogan M., Alkan M., (2003) Removal of methyl violet from aqueous solution by perlite, Journal of Colloid and Interface Science, 267, 32-41.

9. Dogan M., Alkan M., Demirbas O., Ozdemir Y., Ozmetin C., (2006) Sorption kinetics of maxilon blue GRL onto sepiolite from aqueous solutions, Chem. Eng. J., 124, 89-101.

10. Dogan M., Ozdemir Y., Alkan M., (2007), Sorption kinetics and mechanism of cationic methyl violet and methylene blue dyes onto sepiolite, Dye and Pig, 75, 701-713.

11. El Ass K., Laachach A., Alaoui A., Azzi M., (2010), Removal of methylene blue from aqueous solution using Ghassoul, a low-cost adsorbent, Applied Ecology Environmental Research, 8, 153-163.

12. Forgacs E., Cserhati T., Oros G., (2004), Removal of synthetic dyes from wastewaters: a review, Environ. Int., 30, 953-971.

13. Gad H.M.H., El-Sayed A.A., (2009), Activated carbon from agricultural by-products for the removal of Rhodamine-B from aqueous solution, Journal of Hazardous Materials, 168, 1070-1081.

14. Gupta V.K., Suhas (2009), Application of lowcost adsorbents for dye removal - A review, J. Enviro. Manag., 90, 2313-2342.

15. Gürses A., Karaca S., Doar Ç., Bayrak R., Açıkyıldız M., Yalçın M., (2004) Determination of adsorptive properties of clay/water system: methylene blue sorption, J. Colloid Interface Sci., 269, 310-314.

16. Ho Y.S., (2004) Citation review of lagergren kinetic rate equation on sorption reactions, Scientometrics, 59, 171-177.

17. Jiang Y.X., Xu H.J., Liang D.W., Tong Z.F., (2008), Sorption of Basic Violet 14 from aqueous solution on bentonite, C.R. Chim., 11, 125-129.

18. Kadirvelu K., Karthika C., Vennilamani N., Pattabhi S., (2005), Activated carbon from industrial solid waste as an adsorbent for the removal of Rhodamine-B from aqueous solution: Kinetic and equilibrium studies, Chemosphere, 60, 1009-1017.

19. Panneer Selvam P., Preethi S., Basakaralingam P., Thinakaran N., Sivasamy A., Sivanesan S., (2008), Removal of rhodamine B from aqueous solution by sorption onto sodium montmorillonite, $J$. Hazard. Mater., 155(1-2):39-44.

20. Karaoğlu M.H., Doğan M., Alkan M., (2010), Kinetic analysis of reactive blue 221 sorption on kaolinite, Desalination, 256, 154-165.

21. Kuncek I. and Sener S., (2010), Sorption of methylene blue onto sonicated sepiolite from aqueous solutions, Ultrasonics Sonochemistry, 17, 250-257.

22. Langmuir I., (1916) The constitution and fundamental properties of solids and liquids, J Am Chem Soc., 38, 2221-2295.

23. Mane V.S., and Vijay Babu P.V., (2011) Studies on the sorption of Brilliant Green dye from aqueous solution onto low-cost $\mathrm{NaOH}$ treated saw dust, Desalination, 273, 321-329.

24. Mei-Fang Hou, Cai-Xia Ma, Wei-De Zhang, Xiao-Yan Tang, Yan-Ning Fan, Hong-Fu Wan. 2011. Removal of rhodamine B using iron-pillared bentonite, Journal of Hazardous Materials, 186, 11181123.

25. Nollet H., Roels M., Lutgen P., Van der Meeren P., Verstraete W., (2003), Removal of PCBs from wastewater using fly ash, Chemosphere, 53, 655-665. 
26. Ozcan A.S., Erdem B. and Ozcan A. (2005), Sorption of Acid Blue 193 from aqueous solutions onto BTMA-bentonite, Colloids Surf. A: Physicochem. Eng. Aspect., 266, 73-81.

27. Rafatullah M., Sulaiman O., Hashim R. and Ahmad A. (2010), Sorption of methylene blue on low-cost adsorbents: A review, J. of Hazard. Mater., 177, 70-80.

28. Ravi K., Deebika B., Balu K., (2005), Decolourization of aqueous dye solutions by a novel adsorbent: application of statistical designs and surface plots for the optimization and regression analysis, $\mathrm{J}$. Hazard. Mater., B122, 75-83.

29. Sheng J., Xie Y., Zhou Y., (2009), Sorption of methylene blue from aqueous solution on pyrophyllite, Appl. Clay Sci., 46, 422-424.

30. Tahir S.S., Rauf N., (2006). Removal of a cationic dye from aqueous solutions by sorption onto bentonite clay, Chemosphere, 63, 1842-1848.

31. Takahashi N., Tanaka M., Satoh T., Endo T., Shimada M., (1997). Study of synthetic clay minerals. Part IV: synthesis of microcrystalline stevensite from hydromagnesite and sodium silicate, Microp. Mater., 9. 35-42.

32. Wang C.C., Juang L.C., Hsu T.C., Lee C.K., Lee J.F., Huang F.C., (2004), Sorption of basic dyes onto montmorillonite, J. Colloid Interf. Sci., 273, 80-86.

33. Wang L., Zhang J., Zhao R., Li C., Li Y., Zhang C., (2010), Sorption of basic dyes on activated carbon prepared from Polygonum orientale Linn: Equilibrium, kinetic and thermodynamic studies, Desalination, 254, 68-74.

34. Weber W.J., Morris J.C., (1963), Kinetics of sorption on carbon from solution, J. Sanit. Eng. Div. ASCE, 89, 31-59. 